\title{
Оптимизация методов ВЭЖХ контроля антоцианового состава вин и виноматериалов
}

\author{
Дробь А.А. ${ }^{1}$, Васияров Г.Г. ${ }^{2}$, Титова Е.В. ${ }^{2}$, Староверов С.М. ${ }^{1,2}$, \\ Якуба Ю.Ф. ${ }^{3}$, Гугучкина Т.И. ${ }^{3}$ \\ ${ }^{1}$ Московский государственный университет им. М.В. Ломоносова, Москва \\ ${ }^{2} 3$ АО «БиоХимМак СТ», Москва \\ ${ }^{3}$ Северо-Кавказский федеральный научный иентр садоводства, виноградарства, виноделия, \\ Краснодар
}

Поступила в редакцию 26.01.2019 г.

DOI: https://doi.org/10.17308/sorpchrom.2019.19/736

Предложено совместное использование ВЭЖХ-систем с муравьиной и с трифторуксусной кислотами для получения исчерпывающей информации об антоциановом составе вин и виноматериалов. Впервые предложено использование гидрофильной хроматографии (HILIC) для анализа красных вин и виноматериалов. Показаны преимущества использования режима HILIC для предварительной количественной оценки содержания Mvd-3,5-diGlu в винах и виноматериалах. Проведен качественный анализ 13 образцов вин из винограда сорта Каберне-Совиньон. На основе полученных данных сделан вывод о возможности определения сортовой принадлежности вин и виноматериалов с помощью ВЭЖХ-анализа.

Ключевые слова: антоцианы, обращенно-фазовая ВЭЖХ, HILIC, виноматериалы.

\section{Optimization of HPLC methods for control of anthocyanes composition of wines and wine matherials}

\author{
Drob A.A. ${ }^{1}$, Vasiyarov G.G. ${ }^{2}$, Titova E.V. ${ }^{2}$, Staroverov S.M. ${ }^{1,2}$, \\ Yakuba Y.T. ${ }^{3}$, Guguchkina T.I. ${ }^{3}$ \\ ${ }^{1}$ Lomonosov Moscow State University, Moscow \\ ${ }^{2}$ Joint Stock Company «BioChemMack S\&T», Moscow \\ ${ }^{3}$ North Caucasian Federal Research Center of Horticulture, Viticulture, Wine-making, Krasnodar
}

The experimental data on the anthocyanin analysis in wines and wine materials by RP-HPLC were obtained. The effect of different acids (formic, and trifluoroacetic, oxalic, sulfamic, perchloric) on the quality of the separation was established. The joint use of RP-HPLC systems with formic and trifluoroacetic acids to obtain comprehensive information on the anthocyanin composition of wines and wine materials is proposed. But for hybrid grape variety samples the resolution for Mvd-3,5-diGlu is not enough for quantitative analysis. The use of hydrophilic chromatography (HILIC) for the analysis of red wines and wine materials first proposed as alternative to the fluorometric and TLC methods for determination Mvd-3,5-diGlu. The advantages of HILIC mode for preliminary quantitative assessment of Mvd-3,5-diGlu content in wines and wine materials are shown. The analysis confirmed the presence of Mvd-diGlu in one sample in significant amounts (over $100 \mathrm{mg} / \mathrm{l}$ with total anthocyanin content of $\sim 300 \mathrm{mg} / \mathrm{l}$ ). This indicates that this sample of wine is made from a hybrid grape variety. A qualitative and quantitative anthocyanin analysis of 13 varietal wine samples (from Cabernet Sauvignon grapes, Krasnodar region) was carried out using methods of differential spectrophotometry and HPLC. The different quantitative results obtained by spectrophotometry and HPLC were 
demonstrated. To clarify these results, it is planning to use the developed earlier cluster approach that was impossible without complete separation of all forms of anthocyanins.

On the basis of the obtained data, it was concluded that it is possible to determine the varietal belonging of wines and wine materials using HPLC.

Keywords: anthocyanes, reversed-phase HPLC, HILIC, wine materials.

\section{Введение}

Винодельческая продукция, содержащая антоцианы, имеет свои стандарты качества. Состав вина зависит от сорта винограда и места его произрастания, а также от технологии его производства. Количество фенольных соединений является одним из наиболее важных параметров качества красного вина, оно влияет на цвет и вкус данного продукта [1]. При этом антоцианы являются основными соединениями, ответственными за красный цвет молодых вин [1].

Особенностью красных виноградных вин является то, что антоцианы в них представлены, с одной стороны, лишь моно- и диглюкозидами антоцианидинов (преимущественно $\mathrm{Mvd}$ ), a c другой - гидрофобными кумароильными и ацетоильными производными, а также пираноантоцианами, процесс образования которых в винах описан в работе[2].

Одним из показателей качества вина является наличие или отсутствие в нем мальвидин-3,5-диглюкозида. Превышение содержания этого антоциана свидетельствует о том, что вино приготовлено из гибридного сорта винограда. Поэтому анализу Mvd-3,5-diGlu в вине посвящены отдельные исследования [3].

Таким образом, исследование антоцианового состава играет важную роль при идентификации и квалификации вин.

\section{Эксперимент}

Анализ проводили в градиентном режиме на хроматографе Azura (Knauer, Германия) с УФ-детектором и программным обеспечением ClarityChrom (Knauer, Чехия). В работе использовали колонки Диасфер-110-С18, 3.5 мкм, 4.6x150 мм и Kromasil 60-5-HILIC-D, 5 мкм, 4.6x250 мм. Хромато-масс-спектрометр Shimadzu LCMS-2020 (Япония) с программным обеспечением LabSolution (Shimadzu, Германия).

Обращенно-фазовую (ОФ) ВЭЖХ проводили в элюентах на основе: муравьиной кислоты: А - 8.5\% (об.) водный раствор $\mathrm{HCOOH}$; В - HCOOH/ACN/H2O (8.5:40:41.5, об.); сульфаминовой кислоты: А - $0.07 \%$ (об.) водный раствор $\mathrm{NH}_{2} \mathrm{SO}_{3} \mathrm{H} ; \quad$ В - $\mathrm{NH}_{2} \mathrm{SO}_{3} \mathrm{H} / \mathrm{ACN} / \mathrm{H}_{2} \mathrm{O}$ (0.07:40:41.5); трифторуксусной кислоты: А $0.24 \%$ (об.) водный раствор ТФУ; В - ТФУ/АCN/H $\mathrm{H}_{2} \mathrm{O}(0.24: 40: 41.5)$; хлорной кислоты: А - $0.00025 \%$ (об.) водный раствор $\mathrm{HClO}_{4} ; \mathrm{B}-\mathrm{HClO}_{4} / \mathrm{ACN} / \mathrm{H}_{2} \mathrm{O}$ (0.00025:40:41.5); щавелевой кислоты: А - $0.07 \%$ (об.) водный раствор $(\mathrm{COOH})_{2} ; \mathrm{B}$ $(\mathrm{COOH})_{2} / \mathrm{ACN} / \mathrm{H}_{2} \mathrm{O}(0.07: 40: 41.5)$.

Разделение осуществляли в градиентном режиме 10-40\% В за 20 мин. при температуре $35^{\circ} \mathrm{C}$, длине волны $510 \mathrm{Hм}$, скорости потока $0.8 \mathrm{~cm}^{3} / \mathrm{Mин.}$

В гидрофильной хроматографии использовали элюенты A: ACN/TФУ/ $\mathrm{H}_{2} \mathrm{O}$ (98:0.2:1.8, об.) и В: $\mathrm{A} / \mathrm{H}_{2} \mathrm{O}(80: 20$, об.). Градиент $15-100 \%$ В за 30 мин, при температуре $20^{\circ} \mathrm{C}$, длине волны 510 нм, скорости потока $0.8 \mathrm{~cm}^{3} /$ мин.

Для приготовления растворов использовали деионизованную воду, полученную на установке Millipore Simplicity (Millipore, США), удельное сопротивление воды составляло 18.2 МОмхсм, ацетонитрил марки «SuperGradient» (Panreac, Испания), муравьиную кислоту, марки «HPLC» (Fluka, Швейцария), трифторуксусную кислоту, марки «UV» (Panreac, Испания), хлорную кислоту 70\% 
(Sigma-Aldrich, США), ацетат натрия 99\% (Panreac, Испания), соляную кислоту, х.ч. (Сигма Тек, Россия), сульфаминовую кислоту 99.5\% (МСД, Россия).

Исходный виноматериал был профильтрован на нейлоновых фильтрах 0.2 мкм (Agilent, США).

Для гидрофильной жидкостной хроматографии (HILIC) профильтрованные образцы дополнительно разбавляли в 3 раза раствором АСN/ТФУ/ $\mathrm{H}_{2} \mathrm{O}$ (98:0.2:1.8, об.). Идентификацию пиков проводили с помощью стандартных образцов Mvd-Glu (Sigma-Aldrich, Германия), Mvd-diGlu (Sigma-Aldrich, Франция), а также ВЭЖХ-MC.

Образцы 13 красных сухих виноматериалов, произведенные из винограда сорта Каберне-Совиньон на основных винодельческих предприятиях Краснодарского края (в скобках указаны присвоенные нами порядковые номера): ООС «ОлимП» (1), ООО «АПК Мильстрим - Черноморские вина» (2), ЗАО «Славпром» (3), ООО «Союз-вино» (4), ООО «ТВК-Кубань» (5), ООО «Анапские вина» (6), ОАО АПФ «Фанагория» (7), ОП ООО «Кубань-Вино» (8), Филиал АО АМБК «Очаково» (9), ООО «Долина»(10), ФГБНУ СКФНЦСВВ (Ц-37) (11), ФГБНУ СКФНЦСВВ (Ц-5) (12), ФГБНУ СКФНЦСВВ (Микровиноделие) (13) урожая 2017 г., и один образец Амурский Потапенко (ООО «Юбилейная») (14) были получены из Северо-Кавказского федерального научного центра садоводства, виноградарства и виноделия, г. Краснодар.

\section{Обсуждение результатов}

Официальный нормативный подход при разделении антоцианов в красных и розовых винах изложен в OIV [4]. Этот метод подразумевает проведение качественного ВЭЖХ-анализа в обращенно-фазовом режиме 9 антоцианов, а именно: пяти моноглюкозидов дельфинидина, цианидина, петунидина, пеонидина и мальвидина (Dpd-Glu, Cyd-Glu, Ptd-Glu, Pnd-Glu, Mvd-Glu соответственно), а также четырех ацилированных форм, в которых пеонидин и мальвидин содержат глюкозидные остатки, ацилированные уксусной и п-кумаровой кислотами (PndAcGlu, Mvd-AcGlu, Pnd-CmGlu, Mvd-CmGlu). Данный метод не предполагает возможность появления среди «доминирующих» пиков диглюкозидов антоцианов, при этом возможность их присутствия как такового в составе вин не отрицается [5,6]. В этом же нормативном документе предлагается определять Mvd-diGlu c помощью флуориметрии, требующей длительной пробоподготовки.

Известен метод полуколичественного определения Mvd-diGlu c помощью TCX [7]. Однако его погрешность очень велика и может достигать $30 \%$ относительно ВЭЖХ. Кроме того, с использованием как флуориметрии, так и ТСХ, не удается разделять диглюкозиды различных агликонов. Гораздо более удобным и информативным методом в настоящее время является ВЭЖХ. Однако для количественного анализа Mvd-diGlu этот метод до сих пор не применялся.

Для изучения возможности определения сорта винограда по антоциановому составу был выбран набор надежных (из моносортовых виноматериалов) образцов красных вин сорта Каберне-Совиньон разных производителей. Анализ данных образцов в соответствии с официальным нормативным подходом [4] показал, что по количественному содержанию антоцианов образцы существенно различаются (табл. 1). Видно также, что значительно расходятся и результаты расчета содержания антоцианов с использованием ВЭЖХ и СФ (в дальнейшем для уточнения результатов планируется использовать кластерный подход, разработанный нами ранее [8]). При этом в качественном составе антоцианов и их относительном 
процентном содержании значительных расхождений обнаружено не было, за исключением образца 3, в котором относительное процентное содержание Ptd-Glu оказалось выше, чем в остальных образцах (табл.2).

Таблица 1. Содержание антоцианов по результатам ВЭЖХ (система №1) и СФ в образцах 1-13.

\begin{tabular}{|c|c|c|c|c|c|c|c|c|c|c|c|c|c|}
\hline \multirow{2}{*}{ Метод расчета } & \multicolumn{10}{|c|}{ Виноматериалы } \\
\cline { 2 - 13 } & 1 & 2 & 3 & 4 & 5 & 6 & 7 & 8 & 9 & 10 & 11 & 12 & 13 \\
\hline $\begin{array}{c}\text { Сумма по } \\
\text { ВЭЖХ } \\
\begin{array}{c}\text { в пересчете на } \\
\text { Мvd-Glu), } \\
\text { мг/дм }\end{array}\end{array}$ & 62 & 146 & 294 & 27 & 49 & 156 & 234 & 148 & 175 & 132 & 165 & 164 & 235 \\
\hline $\begin{array}{c}\text { Сумма по СФ, } \\
\text { мг/дм }\end{array}$ & 110 & 188 & 374 & 56 & 95 & 216 & 323 & 234 & 258 & 194 & 233 & 256 & 245 \\
\hline
\end{tabular}

Таблица 2. Относительное процентное содержание антоцианов в образцах 1-13 (система с муравьиной кислотой).

\begin{tabular}{|c|c|c|c|c|c|c|c|c|c|c|c|c|c|}
\hline \multirow{2}{*}{ Антоциан } & \multicolumn{13}{|c|}{ Виноматериалы } \\
\hline & 1 & 2 & 3 & 4 & 5 & 6 & 7 & 8 & 9 & 10 & 11 & 12 & 13 \\
\hline Dpd-Glu & $\begin{array}{l}\text { के } \\
0\end{array}$ & $\begin{array}{l}\Omega \\
\text { ஸे }\end{array}$ & $\begin{array}{l}n \\
\sim \\
\forall\end{array}$ & $\underset{\sim}{\stackrel{8}{r}}$ & $\stackrel{\vartheta}{\dot{\gamma}}$ & $\stackrel{\stackrel{8}{\circ}}{\sim}$ & $\frac{\circ}{\sigma}$ & $\begin{array}{l}\text { ț } \\
\text { t. }\end{array}$ & 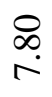 & $\underset{0}{8}$ & $\underset{0}{\sigma}$ & $\underset{0}{8}$ & $\stackrel{m}{\stackrel{n}{n}}$ \\
\hline Cyd-Glu & $\stackrel{ \pm}{\stackrel{0}{0}}$ & $\overline{0}$ & 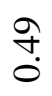 & $\bar{m}$ & $\begin{array}{l}\text { రె. } \\
0\end{array}$ & $\hat{3}$ & तె & ర్ & $\bar{\sigma}$ & $\stackrel{?}{+}$ & $\stackrel{\infty}{\dddot{m}}$ & $\stackrel{\mathscr{n}}{0}$ & $\stackrel{\circ}{\circ}$ \\
\hline Ptd-Glu & $\frac{n}{n}$ & 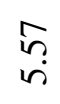 & $\begin{array}{l}8 \\
\text { in }\end{array}$ & $\begin{array}{l}\stackrel{尺}{i} \\
\text { ते }\end{array}$ & $\underset{\sim}{\stackrel{+}{\sim}}$ & $\begin{array}{l}0 \\
\text { t. }\end{array}$ & $\stackrel{\infty}{\sim}$ & $\begin{array}{l}\approx \\
\infty \\
\infty\end{array}$ & 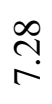 & $\begin{array}{l}\underset{\sim}{\Delta} \\
\infty\end{array}$ & $\begin{array}{l}\vec{N} \\
\stackrel{n}{n}\end{array}$ & 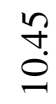 & $\begin{array}{l}\infty \\
\stackrel{\infty}{n}\end{array}$ \\
\hline Pnd-Glu & 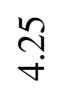 & $\stackrel{\infty}{\stackrel{\infty}{i}}$ & $\stackrel{N}{\mathcal{I}}$ & $\frac{n}{n}$ & & $\frac{\stackrel{I}{m}}{m}$ & $\stackrel{n}{n}$ & $\hat{\sigma}$ & $\begin{array}{l}\underset{f}{f} \\
\dot{r}\end{array}$ & $\begin{array}{l}\stackrel{ }{\infty} \\
\stackrel{i}{i}\end{array}$ & $\underset{\stackrel{\infty}{\infty}}{\infty}$ & $\hat{\alpha}$ & $\underset{\dot{\sigma}}{\vec{\rho}}$ \\
\hline Mvd-Glu & $\begin{array}{l}\stackrel{+}{q} \\
\stackrel{q}{q}\end{array}$ & $\begin{array}{l}\text { กె. } \\
\text { हnं }\end{array}$ & $\begin{array}{l}\hat{\sim} \\
\vec{\lambda}\end{array}$ & $\frac{1}{\dot{q}}$ & $\begin{array}{l}\vec{\nabla} \\
\infty \\
i n\end{array}$ & $\begin{array}{l}\bar{\sigma} \\
\stackrel{\bullet}{n} \\
\stackrel{n}{n}\end{array}$ & $\begin{array}{l}\text { mे } \\
n \\
n\end{array}$ & $\begin{array}{l}\hat{n} \\
\text { है }\end{array}$ & $\frac{F}{i}$ & $\frac{n}{\stackrel{n}{n}}$ & $\begin{array}{l}8 \\
\text { in } \\
\text { in }\end{array}$ & $\hat{\sigma}$ & $\begin{array}{l}\infty \\
\stackrel{\infty}{n} \\
\dot{n}\end{array}$ \\
\hline Pyrano* & $\stackrel{\infty}{\stackrel{\infty}{+}}$ & 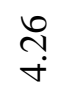 & $\begin{array}{l}n \\
\infty \\
i\end{array}$ & $\stackrel{\leftrightarrow}{r}$ & $\stackrel{\infty}{\stackrel{\infty}{i}}$ & $\hat{\sim}$ & તิ & $\underset{\sim}{\stackrel{J}{N}}$ & $\begin{array}{l}n \\
\infty \\
i\end{array}$ & $\widehat{a}$ & $\underset{n}{n}$ & $\stackrel{\infty}{n}$ & $\begin{array}{l}\text { OD } \\
\text { i }\end{array}$ \\
\hline $\mathrm{Ac}^{* *}$ & $\begin{array}{l}\text { గై } \\
\text { రై }\end{array}$ & $\frac{1}{i d}$ & $\underset{\mathrm{d}}{\mathrm{r}}$ & $\begin{array}{l}\text { mె. } \\
\text { o. }\end{array}$ & $\begin{array}{l}\stackrel{\sim}{\leftarrow} \\
\stackrel{\infty}{\sigma}\end{array}$ & $\begin{array}{l}\bar{\Omega} \\
\tilde{\sim}\end{array}$ & $\begin{array}{l}\infty \\
\stackrel{0}{0} \\
\text { î }\end{array}$ & $\begin{array}{l}\infty \\
\stackrel{\sim}{0} \\
\stackrel{0}{0}\end{array}$ & 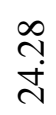 & $\stackrel{\infty}{\stackrel{\infty}{I}}$ & 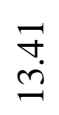 & $\stackrel{\Re}{\infty}$ & 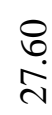 \\
\hline
\end{tabular}

\footnotetext{
* сумма пираноантоцианов; ** сумма ацилированных форм антоцианов.
} 
C нашей точки зрения это объясняется присутствием в составе вина MvddiGlu, одинаковым его удерживанием c Ptd-Glu и наложением соответствующих пиков. Однако добиться приемлемого разделения данных соединений в системе с муравьиной кислотой, которая используется в нормативной документации [4], нам не удалось. Поэтому мы провели оптимизацию официального ВЭЖХ-анализа для установления полного антоцианового состава красных вин. Оптимизацию условий разделения антоцианов проводили на примере образца №14 (Амурский Потапенко), который был выбран как наиболее сложный по составу антоцианов. В его состав сходят как моглюкозиды, так и диглюкозиды антоцианов. В составе элюента были исследованы 5 кислот: муравьиная, щавелевая, трифторуксусная, хлорная и сульфаминовая для достижения необходимой селективности разделения.

В результате было выявлено (рис. 1), что в присутствии щавелевой, сульфаминовой и хлорной кислот в составе элюента Dpd-Glu элюировался одновременно с не идентифицированным пока соединением (возможно, с каким-то диглюкозидом антоцианидина). В системе с муравьиной кислотой не удавалось разделить Mvd-diGlu и Ptd-Glu. В то же время в системе с ТФУ были найдены условия разделения всех указанных выше антоцианов, кроме Pnd-diGlu и Mvd-diGlu, первый из которых в сухих красных винах встречается редко. Таким образом, для расширенного исследования состава антоцианов в винах необходимо совместное использование двух систем: с муравьиной и трифторуксусной кислотами. Это позволяет провести полный качественный анализ антоцианового состава красных вин, но недостаточно для количественного определения глюкозидов пианидина и мальвидина (рис.1).

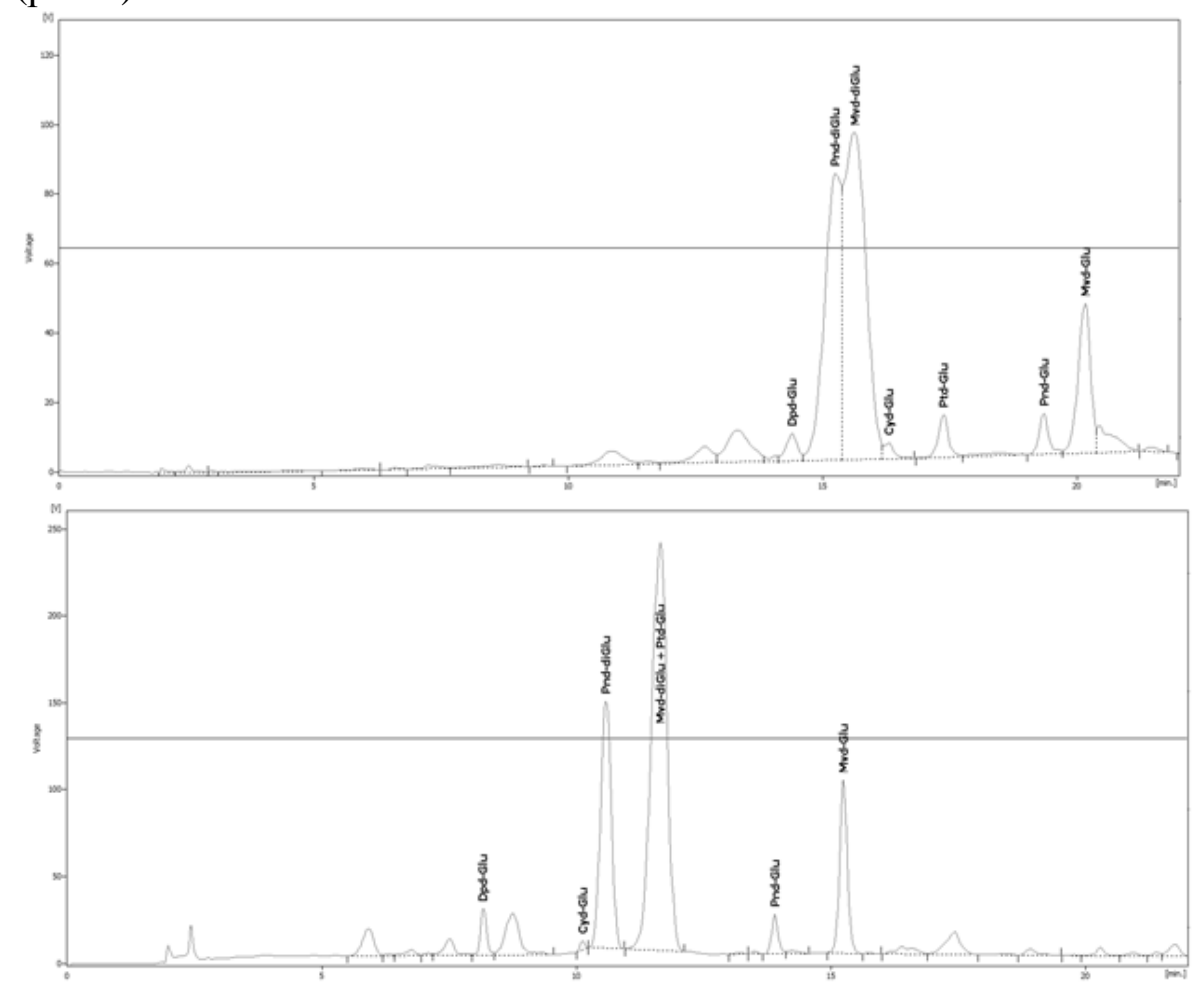

Рис. 1. Хроматограммы образца №14, полученные в системах с муравьиной кислотой (верхняя) и трифторуксусной кислотой (нижняя).

В связи с особым интересом к содержанию мальвидин-3,5-диглюкозида в винах мы исследовали и принципиально иную по селективности систему на основе гидрофилизованного силикагеля, где в качестве элюента использовали ацетонитрил с добавками водного раствора ТФУ. В этих условиях реализуется механизм HILIC, 
основанный на гидрофильных взаимодействиях. Ранее на примере разделения соединений с разным количеством углеводных фрагментов [9] было показано, что этот подход обеспечивает высокую селективность к такого рода соединениям. Использование данного режима для определения диглюкозидов антоцианов в винах и виноматериалах оказалось исключительно продуктивным. В этом режиме моноглюкозиды и диглюкозиды антоцианов разделяются между собой, но не разделяются по агликонам (рис. 2), т.е.режим HILIC является наиболее удобным для принципиального обнаружения диглюкозидов антоцианов в образцах, а также не требует дополнительной пробоподготовки, что значительно сокращает время проведения анализа, в отличие от подходов с использованием флуориметрии и ТСХ.
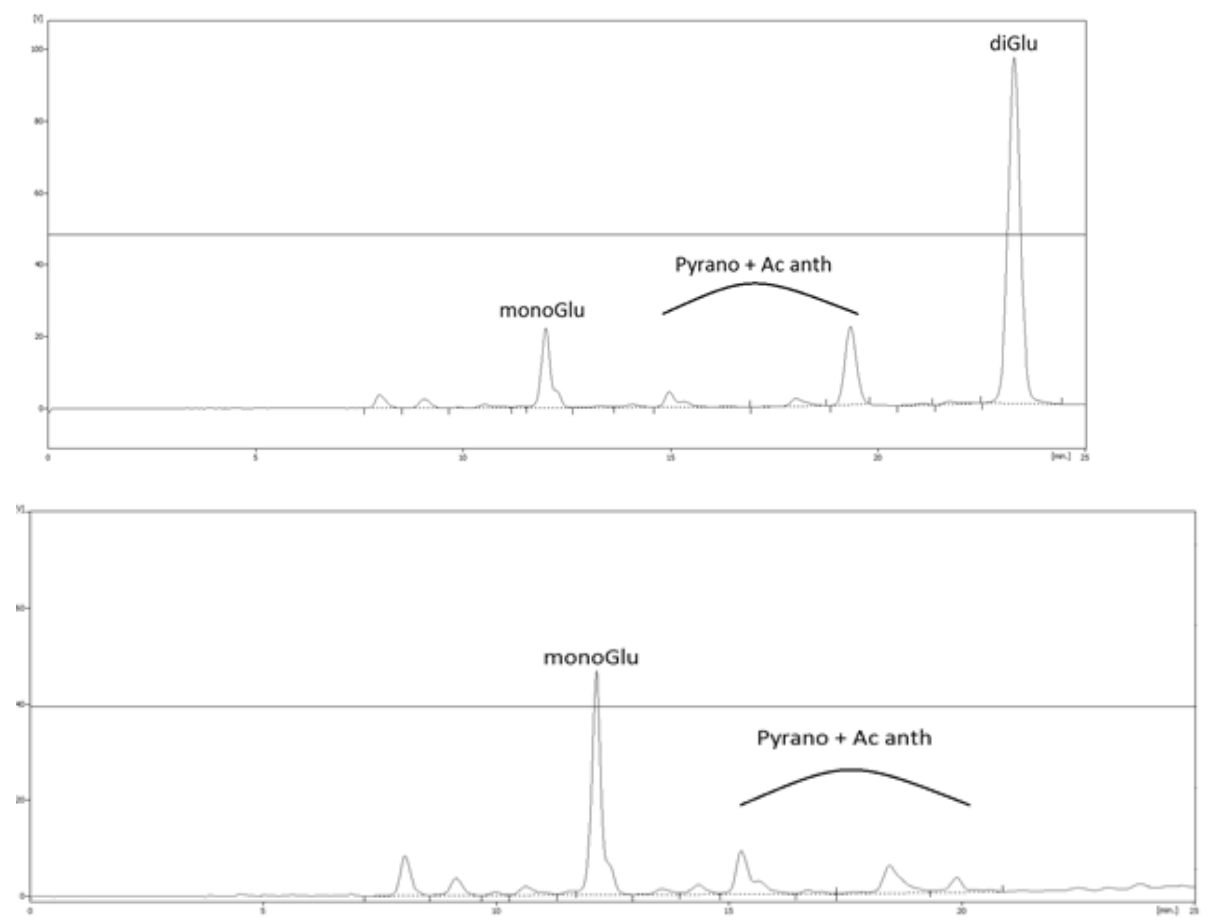

Рис. 2. Хроматограммы образца №14 (верхняя) и образца №1 (нижняя) в системе HILIC.

На рис. 2 видно, что диглюкозиды антоцианов надежно отделяются от моноглюкозидов антоцианов, пираноантоцианов и ацилированных форм антоцианов. Также стоит отметить, что в отличие от ОФ-ВЭЖХ, форму градиента в гидрофильной хроматографии для достижения приемлемого разделения подобрать значительно легче.

Содержанию мальвидина-3,5-диглюкозида (Mvd-diGlu) в винах на рынке EC уделяют особое внимание, определяя его предельно допустимую концентрацию на уровне 15 мг/дм ${ }^{3}[10]$.

Анализ подтвердил присутствие Mvd-diGlu в образце №3 в значительных количествах (свыше 100 мг/л при общем содержании антоцианов в данном образце $\sim 300 \mathrm{мг} /$ дм $^{3}$ ). Это свидетельствует о том, что данный образец вина произведен из гибридного сорта винограда.

\section{Заключение}

Предложено совместное использование ОФ ВЭЖХ-систем с муравьиной и с трифторуксусной кислотами для получения дополнительной информации о составе 
вин и виноматериалов. Показано, в режиме HILIC эффективно отделяются диглюкозиды, что позволяет использовать этот подход для предварительной количественной оценки содержания Mvd-diGlu в винах и виноматериалах.

В данной работе выявлено, что качественный состав тринадцати образцов вин из винограда сорта Каберне-Совиньон, практически одинаков (за исключением образца №3). Это позволяет сделать предположение о возможности определения сортовой принадлежности вин и виноматериалов с помощью ВЭЖХ-анализа.

\section{Исследование выполнено при финансовой поддержке РФФИ в рамках научного проекта № 18-34-00815.}

\section{Список литературы}

1. Motohashi N. Anthocyanins: Structure, biosynthesis and health benefits. NovaSciencesPublishersInc. 2012. pp. 1-22, 283-298.

2. de Freitas V., Mateus N. // Anal. Bioanal. Chem. 2011. Vol. 401. pp. 1463-1473.

3. de Quirós R.-B.A., López-Hernández J., Lage-Yusty M.A.. // The Open Food Sci. J., 2008. Vol. 2. pp. 68-71.

4. Compendium of International Methods of Wine and Must Analysis. 2013. Vol. 2. OIVMA-AS315-11: R2007 HPLC-Determination of nine major anthocyanins in red and rosé wine.

5. Heier A., Blaas W., Droß A., Wittkowski R. // Am. J. Enol. Vitic., 2002. Vol. 53. pp. 7886.

\section{References}

1. Motohashi N. Anthocyanins: Structure, biosynthesis and health benefits. NovaSciencesPublishersInc. 2012. P. 1-22, 283298.

2. de Freitas V., Mateus N., Anal. Bioanal. Chem., 2011, Vol. 401, pp. 1463-1473.

3. de Quirós R.-B.A., López-Hernández J., Lage-Yusty M.A., The Open Food Sci. J., 2008, Vol. 2, pp. 68-71.

4. Compendium of International Methods of Wine and Must Analysis, 2013, Vol. 2, OIVMA-AS315-11: R2007 HPLC-Determination of nine major anthocyanins in red and rosé wine.

5. Heier A., Blaas W., Droß A., Wittkowski R., Am. J. Enol. Vitic., 2002, Vol. 53, pp. 78-86.

Дробь Александр Александрович - аспирант, химический факультет МГУ им. М.В.Ломоносова, Москва

Васияров Георгий Георгиевич - зав. отделом хроматографии, ЗАО «БиоХимМак СТ», Москва

Титова Елена Владимировна - к.х.н., ведущий научный сотрудник, ЗАО «БиоХимМак
6. Wulf L.W., Nagel C.W. // Am.J.Enol.Vitic. 1978. Vol. 29. pp. 42-49.

7. Сластья Е.А., Жилякова Т.А., Аристова Н.И., Ткачёв И.Ф. и др. // Вестник Харьковского Наџионального Университета. 2005. Вып. 13(36). № 669. С. 119-124.

8. Васияров Г.Г., Дробь А.А., Титова Е.В., Староверов С.М. // Сорбционные $u$ хроматографические проиессы. 2017. Т. 17. № 2. С. 243-249.

9. Дейнека В.И., Саенко И.И., Дейнека Л.А., Блинова И.П. // ЖАХ. 2016. Т. 71. № 3. C. 310-314.

10. ЕС № 1493/1999, Статья 19 и ЕС № 883/2001, Статья 21.
6. Wulf L.W., Nagel C.W., Am.J.Enol.Vitic., 1978, Vol. 29, pp. 42-49.

7. Slast'ya E.A., Zhilyakova T.A., Aristova N.I., Tkachev I.F. et al., Vestnik Khar'kovskogo Natsional'nogo Universiteta, 2005, Vyp. 13(36), No 669, pp. 119-124.

8. Vasiyarov G.G., Drob' A.A., Titova E.V., Staroverov S.M., Sorbtsionnye $i$ khromatograficheskie protsessy, 2017, Vol. 17, No 2,pp. 243-249.

9. Deineka V.I., Saenko I.I., Deineka L.A., Blinova I.P., ZhAKh, 2016, Vol. 71, No 3, pp. 310-314.

10.ES № 1493/1999, Stat'ya 19 i ES № 883/2001, Stat'ya 21

Drob' Alexander A. - PhD Student, Chemistry Department, Lomonosov State University, Moscow

Vasiyarov Georgy G. - Head of chromatography department, JSC «BioChemMack S\&T», Moscow

Titova Elena V. - PhD (chemistry), Leadering Researcher, JSC «BioChemMack S\&T», Moscow 
СТ», Москва

Староверов Сергей Михайлович - д.х.Н., генеральный директор ЗАО «БиоХимМак СТ», зав. лаб. «Новые химические технологии для медицины», Химический факультет МГУ им. М.В.Ломоносова, Москва

Якуба Юрий Федорович - д.Х.н, ведущий научный сотрудник, заведующий ЦКП «Приборно-аналитический», Северо-Кавказский федеральный научный центр садоводства, виноградарства, виноделия, Краснодар

Татьяна Ивановна Гугучкина - д.с-х.н, профессор, заведующая научным центром виноделия, Северо-Кавказский федеральный научный центр садоводства, виноградарства, виноделия, Краснодар
Staroverov Sergei M. - grand $\mathrm{PhD}$ (chemistry), CEO JSC «BioChemMack S\&T», Head of Laboratory «New chemical technologies for medicine», Chemistry Department, Lomonosov State University, Moscow, e-mail: staroverov@bcmt.ru

Yakuba Yuri T. - grand $\mathrm{PhD}$ (chemistry), Leadering Researcher, Head of core facilities «Instrumental and Analytical», North Caucasian Federal Research Center of Horticulture, Viticulture, Wine-making, Krasnodar

Guguchkina Tatyana I. - grand $\mathrm{PhD}$ (agriculture), professor, Head of the scientific center of winemaking, North Caucasian Federal Research Center of Horticulture, Viticulture, Wine-making, Krasnodar 